\title{
Investigating the Relationship of Creative Educational Atmosphere and Academic Self-efficacy with Problem Solving Skills of Higher Education Students
}

\section{Ezzatollah Ghadampour}

Assistant professor of Educational Psychology. Khorramabad, Kamalvand, Lorestan University, Faculty of Humanities

Email: Hveiskarami86@yahoo.com

\section{Hassan Ali Vieskarami}

Assistant professor of Educational Psychology. Khorramabad, Kamalvand, Lorestan University, Faculty of Humanities Email: eghadampour@yahoo.com

\section{Houshang Garavand*}

PhD student of Educational Psychology, Lorestan University, Faculty of Humanities Email: hoshanggaravand@gmail.com

Doi:10.5901/mjss.2016.v7n4s1p188

\section{Abstract}

\begin{abstract}
The aim of the present study is to investigate the relationship of creative educational atmosphere and academic self-efficacy with problem solving skills of higher education students. The research method of the study is correlational. The population of the study includes all MA/MSc students of Lorestan University as 1643 individuals among which 310 participants were selected via Krejcie and Morgan's table using the stratified random sampling proportionate to the size sampling method. To collect data, the Creative Educational Atmosphere Inventory developed by Mohebbi et al. (2013), the Problem-Solving Inventory (Heppner \& Peterson, 1982) and the self-efficacy beliefs Inventory of Žáková et al. (2005) were used. To analyze data, Pearson correlation coefficient and regression analysis were used. The results obtained from the correlation coefficient indicated that there is a significant correlation of creative educational atmosphere and academic self-efficacy. In addition, the results of multiple regression indicated that from among sub-components of creative educational atmosphere, only subcomponent of trust and from among subcomponents of academic self-efficacy, two subcomponents of trust to one's own ability to interact with others in University and trust to one's own ability to do homework can predict problem solving skills. The results of the present study confirm the role of creative educational atmosphere and academic self-efficacy on problem solving skills of university students.
\end{abstract}

Keywords: creative educational atmosphere, problem solving skills, academic self-efficacy.

\section{Statements of the problem}

Higher education in each country is one of the factors affecting the advancement of that country in cultural, social, political and educational grounds. Regarding the everyday expansion of scientific development and tendency of private and public organs for attracting experts, the individuals in each society have tended towards universities and academic centers (Aboma, 2009). One of the most important issues in higher education is problem solving skills. Problem solving is a cognitive process by which an individual tries to find a solution for a problem (Perla \& Odanel, 2004). In this definition, problem solving is considered as a conscious, rational, and purposive activity. This process provides effective and potential solutions for solving a problem and increases the possibility of selection of effective solutions from among different solutions. Problem solving is considered as a general coping strategy which facilitates compatibility and competition. Problem solving means involvement in the task whose solution is not clear. During recent years, the problem solving therapeutic approach as an intervention has concentrated on compatibility and training attitudes and skills of problem solving (Akinsola, 2008; Atadokht, Norouzi, and Ghaffari, 2013). Problem solving is a coping and practical skill which results in the increase in self-confidence and is related to personal compatibility including five steps: perceiving oneself, defining the problem, preparing a list of different solutions, decision making about the most appropriate solution, and trying the selective solution (Bell \& D'zurilla, 2009). Among factors affecting problem solving, variables of self-efficacy and creative educational atmosphere can be referred to. 
In the cognitive-social theory, it is hypothesized that self-efficacy beliefs in determining activities followed by individuals is the degree of efforts which they adopt for pursing activities and distinct levels of individuals' resistance against potential barriers is important (Gore, 2006). Reviewing literature attentively indicates that the concept of selfefficacy has been widely used in different research realms (Perry, DeWine, Duffy \&Vance, 2007). Bandura (2001) believes that to predict individuals' problem solving performances in different domains such as schools, work, and relations, self-efficacy plays an important role. There is an interventional and interactional relationship between problem solving skills and self-efficacy. Therefore, it seems that the more individuals' self-efficacy, the more their problem solving power (Narimani \& Vahidi, 2013).

From among factors affecting other problem solving skills in the educational atmosphere in which learning occurs. Ekvall (1996) believes that an educational environment includes a set of attitudes, feelings, and behaviors emphasizing innovation, satisfaction, and efficacy of individuals. In his study, Ekvall considers ten factors of challenge, freedom, supporting of ideas, trust and confidence, discussion, conflict, risk taking, give chances to ideas, vibrancy, and joy and humor to be effective on creating a creative environment (Ekvall, 1996). By challenge in Ekvall's theory (1999), it means a degree of emotional involvement of members of a class in realizing objectives. Therefore, in educational environments which are challengeable, students reach the meaningfulness of beliefs and are motivated by their teachers to do activities. By freedom, it means independence of members in their behaviors. Therefore, students are motivated to find information and solve their problems. By supporting ideas, it means new methods of behaviors with ideas. To realize this issue, professors should provide an environment in which multiple idea can be provided in order that individuals hear idea of each other. By trust and confidence, it means emotional trust between members in interactions with each other. In this environment, professors act in such a way that students without fear of being ridiculed by their classmates and professors, can present their ideas. In environments in which professors provide spaces for discussions and motivate these spaces, a lot of ideas can be presented by students in classes whose outputs include creation of new ideas (Ekvall, 1999). In environments where contradiction is high, individuals cannot tolerate each other. Therefore, in the teaching method in which contradiction is low, professors provide a space in the class which make students to tolerate contradictory beliefs. Risk taking means the tolerance of uncertainty in classes. In the teaching method which is full of risk taking, professors and students present and perform new ideas. By giving chances to ideas, it means the time given to students by students to explain and describe their new ideas in the class where teaching methods are full of vivacity and dynamics. Usually, there are dynamics and vivacity among members of a class and new events occur in classes. In environments having vivacity and happiness, individuals feel convenience in classes (Ekvall, 1999).

By reviewing the literature, no research which has directly investigated the relationship of creative educational atmosphere and self-efficacy beliefs with higher education students' problem solving skills was found. However, some studies have been conducted in relation with mentioned variables. For example, Hungies \& Changeiywo (2009) indicated that the strategy of creative teaching is significantly effective on the motivation of learners and creative planning skills. Aschen Brener (2008) indicated about creative teaching of professors and behaviors of students that students consider the role of creative professors as effective on providing creativity in the educational system. Results of the study of Dau Gaspar (2011) emphasized the significance of creative approaches of teachers in shaping creativity among students which was accessing educational aims or creative personality. Koslowsky et al. (2009) investigated the relationship of self-efficacy and providing successful models and group activities of teachers and indicted that there is a significant relationship between providing successful models and group activities of teachers. Nasir, Saleh Sedghpour, and Cheraghian Radi (2014) concluded that self-efficacy has direct effects on evaluating problem solving and indirect effects on metacognitive mediation. Mahmoudi, Pasargadi, and Ebadi (2009) obtained the results that professors' behaviors and supports result in creating motivation for doing research and the frequency, quality, and confirmation of student-professor interactions have significant effects on intellectual development of students.

Therefore, the issue resulting in doing the present study was that most of the conducted studies have dealt in the separate effect of interpersonal and intrapersonal variables on problem solving skills in students and the issue of the effect and interaction of these two variables has received less attention. Importantly, Lorestan University is emerging in terms of higher education and therefore, there is no accurate data about psychological, environmental, and educational processes affecting higher education students' problem solving skills. Therefore, according to findings, it can be hypothesized that creative educational atmosphere and academic self-efficacy are significantly and passivity effective on problem solving skills. 


\section{Research Hypotheses}

1. There is significant and positive correlation of perception of creative educational atmosphere and problem solving skills among higher education students.

2. There is significant and positive correlation between academic self-efficacy and problem solving skills among higher education students.

\section{Method}

The research method is descriptive-correlational. The population of the present study include all MA/MSc students of Lorestan University in the academic year 2015-2016 as 1643 individuals. According to Krejcie and Morgan's table, from the population, 310 participants were selected using the stratified random sampling proportionate to the size method in terms of faculty and gender. To collect data the following instruments were used.

\subsection{The Creative Educational Atmosphere Inventory}

To assess the creative educational atmosphere, the inventory developed by Mohebbi et al. (2013) was used. They used 10-component Ekvall's creative atmosphere. Since main items of the questionnaire developed by Ekvall is consistent with assessing creative atmosphere, the researcher tried to present some questions for assessing creativity in teaching with regard to main components of the research. Therefore, the researchers, after developing the primary questionnaire and doing some necessary modifications, to assess its content validity, it was submitted to eight experts of educational sciences and psychology of Ferdowsi University of Mashhad. Then, amendments were conducted according to their comments. By considering the ideas of the experts and changing some items, the final inventory was developed. To ensure the formal validity of the questionnaire, it was administered on a small group of students and they were asked to identify unclear questions. After determining ambiguous questions, to clarify them, some modifications were conducted on the questionnaire and the final version were submitted to participants. To evaluate the reliability the questionnaire, Cronbach's alpha was employed and its coefficient was as 0.85 . The final version of the inventory included 10 components and 55 items. Challenge (8 questions), freedom (6 questions), supporting ideas (6 questions), trust and confidence (11 questions), discussion (6 questions), conflict (5 questions), risk taking (4 questions), giving chance to ideas (4 questions), vibrancy (3 questions), and joy and humor (2 questions) were its components and their questions. The scoring scale of the questionnaire was based on five-point Likert scale (strongly disagree, disagree, no idea, agree, and strongly agree). Therefore, score 1 indicates the minimum tendency and score 5 indicates the maximum positive tendency. Accordingly, the total score of the questionnaire ranges between the minimum score 1 to the maximum score as 275 . The mode of calculating the cross section was that because values of items were as strongly disagree $=1$, disagree $=2$, no idea $=3$, agree $=4$, and strongly agree $=5$, the sum of scores of options was 15 and by dividing it on the number of options (five options), 3 can be obtained.

\subsection{Problem Solving Questionnaire}

Heppner and Korsakov (1987) considered problem solving to contain a set of behavioral, cognitive, and emotional responses represented for compatibility with internal and external challenges. Heppner (1988) presents the existence of three structures in the process of problem solving including as: feeling competent in problem-solving, personal control over emotions and behaviors, and attitudinal-avoidant styles. In this regard, some research and theoretical evidence has been presented about metacognitive variables particularly the evaluation of oneself as an effective variable in problem solving. The Problem Solving Inventory of Heppner and Peterson (1982) has been developed for assessing the perception of respondents to their behaviors in problem solving. This questionnaire includes 35 items designed for measuring how individuals react to their own everyday issues. 3 items $(9,22$, and 29) of the questionnaire are for research objectives and are not scored. The Problem Solving Questionnaire can be divided into three sub-scales based on the factor analysis rotation:

Trust in solving problems with 11 items $(5,10,11,12,19,23,24,27,33,34$, and 35), attitudinal-avoidant style with 16 items $(1,2,4,6,7,8,13,15,16,17,18,20,21,28,30,31)$, and personal control with 5 items $(3,14,25,26$, and 32$)$. This questionnaire is based on 6-point Likert scale with low scores indicating the highest level of knowledge of ability to solve problems (1=strongly agree, 2=moderately agree, $3=$ slightly agree, 4=slightly disagree, 5=moderately disagree, $6=$ strongly disagree). To prevent biases in answering, items $11,34,1,2,4,13,15,17,21,30,3,25,26$, and 32 are 
presented in negative items. The total score of the questionnaire is obtained from the sum of all answers. This questionnaire has been tested with several samples of subjects. It enjoys a relatively high internal consistence with alpha values 0.72 to 0.85 in subscales $P C=0.72, A A=0.84, P S C=0.85$, and 0.90 for the total scale (Heppner \& Peterson, 1982). The test-retest reliability of the total score of the questionnaire between two weeks was reported to be in the range of 0.83 to 0.89 . This issue indicates that the questionnaire is reliable for assign the ability to solve problems. This questionnaire was used by Rafati (1996) under the supervision of Khosravi in Iran (Khosravi et al. 1998). Cronbach's alpha obtained in the study of Khosravi et al. (1998) is 0.86 which is acceptable.

\subsection{Academic self-efficacy beliefs}

The self-efficacy beliefs Inventory of Žáková et al. (2005) have developed a new version of the Academic Self-Efficacy Inventory by using the academic scale of Middleton, Lent, Brown, \& Larkin (1986) and the a College Self-efficacy Scale (Solberg et al. 1993). In this scale, the concept of academic self-efficacy beliefs are measured via 27 tasks related to the university. In this scale, participants are asked to identify their own degree of confidence in doing successfully each of the 27 academic tasks based on a 10-point Likert scale ranges from "strongly unconfident" as 1 to "strongly confident" as 10. In Žáková et al. (2005), the results of confirmatory factor analysis indicated four factors of confident to one's own ability in doing tasks in class (items $8,13,10,18,11,6,9,22$, and 16), confident to one's own ability in doing tasks outside class (items $3,5,1,15,4,25,17$, and 27), confidence to one's own ability in interacting with others in the university (items 20 , $23,2,26,7$, and 21), and confidence to one's own ability in managing at work, family, and university (items 9, 14, 24, and 12). In addition, they estimated reliability of subscales of this questionnaire as 0.72 and 0.90 . This questionnaire was normalized by Shokri et al. (2011) in Iran. They confirmed the four mentioned factors using confirmatory factor analysis. In addition, using Cronbach's alpha coefficient, the reliability was reported as follows: confident to one's own ability in doing tasks in class as 0.88 , confident to one's own ability in doing tasks outside class as 0.85 , confidence to one's own ability in interacting with others in the university as 0.83 , and confidence to one's own ability in managing at work, family, and university as 0.72 .

\section{Research Findings}

Descriptive findings of the research includes statistical indicators such as mean and SD for variables of the study. The total number of the student participating in the study were 310 individuals. Their mean scores and SD in the Creative Educational Atmosphere Scale is equal as (169.39 \pm 33.32$)$, in the subscale of challenge is $(25.55 \pm 5.94)$, freedom as

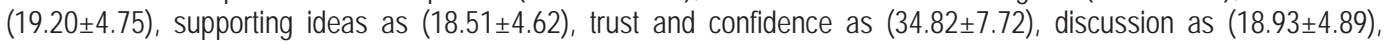
conflict as (14.73 \pm 3.43$)$, risk taking as (11.26 \pm 2.90$)$, giving chances to ideas as (11.96 \pm 3.58$)$, vibrancy as $(8.52 \pm 2.66)$, and joy and humor as (5.86 \pm 2.19$)$. in addition, mean scores and SD in academic self-efficacy is equal as (174.43 \pm 34.40$)$, in confident to one's own ability in doing tasks in class as $(56.80 \pm 12.53)$, confident to one's own ability in doing tasks outside class as (51.48 \pm 10.56$)$, confidence to one's own ability in interacting with others in the university as (41.18 \pm 9.59$)$, and confidence to one's own ability in managing at work, family, and university as (122.11 \pm 13.78$)$.

To investigate the relationship between creative educational atmosphere and problem solving skills, Pearson correlation coefficient was used and its results are represented in table 1:

Table 1: correlation between creative educational atmosphere and problem solving skills

\begin{tabular}{|c|c|}
\hline Problem solving scales & Variables \\
\hline $0.26 * *$ & Creative educational atmosphere \\
\hline $0.12 *$ & Challenge \\
\hline $0.22 * *$ & Freedom \\
\hline $0.27 * *$ & Supporting ideas \\
\hline $0.40 * *$ & Trust and confidence \\
\hline $0.15 * *$ & Discussion \\
\hline 0.007 & Conflict \\
\hline $0.14 *$ & Risk taking \\
\hline $0.20 * *$ & Giving chances to ideas \\
\hline 0.08 & vibrancy \\
\hline $0.19 * *$ & Joy and humor \\
\hline correlation at $p<0.05 *$ & correlation at $p<0.01 * *$ \\
\hline
\end{tabular}


As the results of table 1 indicate, the correlation coefficient between the total scale of creative educational atmosphere and subscales of challenge, freedom, supporting ideas, trust and confidence, discussion, conflict, risk taking, giving chances to ideas, vibrancy, and joy and humor are positively and significantly correlation with problem solving skills $(p<0.01)$. But no significant correlation was observed between components of conflicts and vibrancy and problem solving skills $(p>0.05)$.

As follows, the results of multiple regression is presented for predicting problem solving skills via subcompacts of creative educational atmosphere in the form of table 2 :

Table 2: results related to multiple regression analysis of problem solving skills based on subcomponents of creative educational atmosphere

\begin{tabular}{cccccc}
\hline Sig. & $\mathbf{F}$ & Mean squares & df & Sum of squares & Model \\
0.0001 & 8.46 & 1294.45 & 10 & 12944.48 & Regression \\
& & 152.99 & 299 & 45746.56 & Remainder \\
& & & 309 & 58691.05 & Total \\
\hline
\end{tabular}

Results of table 2 indicate that subcomponents of creative education atmosphere can predict students' problem solving skills $(F(10,299)=8.46, p<0.01)$. In addition, the results indicate that the square of correlation coefficient is equal as $\mathrm{R} 2=0.47$. This issue indicate that predicting variables can explain $47 \%$ of the variations of the criterion variable (problem solving skills). Standardized regression coefficient also indicated that from subcomponents of creative educational atmosphere, trust and confidence with beta coefficient as 0.56 can positively predict problem solving skills ( $\mathrm{t}=6.32$, $\mathrm{p}<0.01)$.

To investigate the relationship between academic self-efficacy and problem solving skills, Pearson correlation coefficient was used. Table 3 indicates the results as follows:

Table 3: correlation between academic self-efficacy and problem solving skills

\begin{tabular}{cl}
\hline Problem solving skills & Variables \\
\hline $0.48 * *$ & Academic self-efficacy \\
$0.38 * *$ & confident to one's own ability in doing tasks in class \\
$0.47 * *$ & confident to one's own ability in doing tasks outside class \\
$0.56 * *$ & confidence to one's own ability in interacting with others in the university \\
$0.22 * *$ & confidence to one's own ability in managing at work, family, and university \\
\hline
\end{tabular}

correlation at $p<0.01 * *$

As the results of table 3 indicate, correlation coefficient between the total scale of academic self-efficacy and subcomponents of confident to one's own ability in doing tasks in class, confident to one's own ability in doing tasks outside class, confidence to one's own ability in interacting with others in the university, confidence to one's own ability in managing at work, family, and university have positive and significant correlation with problem solving skills $(p<0.01)$.

Below, the results of multiple regression for predicting problem solving skills via subcomponents of academic self-efficacy is presented in table 4:

Table 4: result related to multiple regression analysis of problem solving skills based on subcompacts of academic selfefficacy

\begin{tabular}{cccccc}
\hline Sig. & $\mathbf{F}$ & Mean of squares & df & Sum of squares & Model \\
\hline 0.0001 & 41.80 & 5196.15 & 4 & 20784.63 & Regression \\
& & 124.28 & 305 & 37906.41 & Remainder \\
& & 309 & 58691.05 & Total \\
\hline
\end{tabular}

Results of table 3 indicate that subcomponents of creative educational atmosphere can predict students' problem solving skills $(F(10,299)=8.46, p<0.01)$. In addition, the results indicate that the square of the correlation coefficient is as $\mathrm{R} 2=0.47$. This issue indicates that predictors can explain $47 \%$ of the variations of the criterion variable (problem solving 
skills). Standardized regression coefficient also indicated that from subcomponents academic self-efficacy, confidence to one's own ability in interacting with others in the university with the beta coefficient as $0.50(t=7.29, p<0.01)$, and confident to one's own ability in doing tasks outside class with the beta coefficient as 0.50 can positively be an appropriate predictor for problem solving skills $(t=3.41, p<0.01)$.

\section{Discussion and Conclusion}

Problem solving has been always a part of primary thoughts of human beings and has been remained as an important dimension of humans' lives. The issue can be defied as a question, issue, or situation which should be investigated and answered. The success in performance of solving problem causes the superiority in educational spaces such as schools and university. In addition, individuals in everyday situations and outsides class face different issues. Solutions and answers which we produce and decisions which we make not only influence the outcome of a particular situation, but also potentially influence personal and social advancement and our orientations in life significantly (Knowles, 2000). Therefore, the main objective of the present study is to investigate the relationship between educational atmosphere and academic self-efficacy with problem solving skills of students of higher education in Lorestan University.

The results of Pearson correlation coefficient indicated that there is a significant and positive correlation of perception of creative educational atmosphere and problem solving skills of higher education students. Furthermore, standardized regression coefficient indicated that from among subcomponents of creative educational atmosphere only trust and confidence with beta coefficient as 0.56 can positively predict problem solving skills.

These findings are consistent with those of Mahmoudi, Pasargadi, and Ebadi (2009), Dao Gaspar (2011), Hungies \& Changeiywo (2009), and Aschen and Brener (2008). One of the main elements in university is the issue of training and teaching-learning process. Regarding the advancement in technologies and the advent of post-industrialism, it is necessary that the teaching-learning process in universities and schools be coordinated with these upheavals and traditional strategies of transferring information should move towards new educational strategies of problem-orientedness and problem-solving which can result in developing creative abilities in students. This issue is very important for MA/MSc students because these individuals enjoy high abilities and they can be trained with effective methods in order that their visions be expanded and consequently, their power of analyzing issues, criticizing scientifically, and solving problems can be improved. Usually, teaching and learning methods can be divided into two groups of active and passive methods. Naturally, creativity-based educational strategies are related to the first group. Active methods are interactive in which learners play an active role in the process of learning and teacher have the role of a guider (Torrance, 1990; Kerka \& Gory, 1990). It should be noted that although professors' curricula are pre-designed and prepared for them, there is this possibility that regarding students' capabilities and professors' identification, some changes can occur in them. In addition, professors can use active teaching methods for enriching students' conditions and abilities because as mentioned, active teaching methods provide necessary opportunities for developing creative thought skills and problem solving as many as possible.

The results of Pearson correlation coefficient indicated that there is a significant and positive correlation of selfefficacy with problem-solving skills of higher education students. Standardized regression coefficient also indicated that from subcomponents academic self-efficacy, confidence to one's own ability in interacting with others in the university with the beta coefficient as 0.50 ( $t=7.29, p<0.01)$, and confident to one's own ability in doing tasks outside class with the beta coefficient as 0.50 can positively be an appropriate predictor for problem solving skills $(t=3.41, p<0.01)$. These findings are consistent with those of Nasri, Saleh Sedghpour, and Cheraghian Radi (2014). According to findings of Bandura (2001), self-efficacy affects thought patterns and to cope with complicatedness of multidimensional data processing and problem solving process, individuals should have high self-efficacy in order to be self-efficient in complicated decision making situations and in analytical thoughts. The higher the individual's self-efficacy beliefs, the more he exerts efforts for cognitive processing of working and thinking analytically. Individuals with low levels of selfefficacy, in case of facing difficulties, reduce their efforts and are surrounded by low-level strategies. In addition, Bandura (2001) believes that to predict the performance of individuals' problem solving in different domains such as schools, work, and social interactions, self-efficacy has a great role. Between problem-solving skills and self-efficacy there is an interventional and interactional relation. Therefore, it seems that the higher individuals self-efficacy, the more their power of problem solving (Narimani \& Vahidi, 2013).

Among limitations of the study, one can refer to the quantitative research method because qualitative research conducted via structure, semi-structure, and non-structured interviews, the researcher can find deeper finings. If changes in research objectives provide this possibility that qualitative methods conducted via interviews can be used, more complete results can be obtained. In addition, the relatively low number of the population was among research limitations. 
Due to high costs and time-consuming nature of the research, as well as the proportionate of the population to the sample size, the study was limited to MA/MSc students. The relationship of creative educational atmosphere and selfefficacy with problem solving skills in Iran has received little attention. Therefore, the results of the present study can be compared with the results obtained in other countries and relatively similar studies in Iran. This issue can create some problems in discussion and conclusion section of the study particularly in case of presenting consistent and inconsistent researchers because there was no researches totally related to the subject of the research in Iran and abroad. In addition, collecting data was self-report. Therefore, interpretation of the results of the study should be conservatively represented. Regarding the results obtained, it is suggested that professors should have some changes in their teaching methods and by giving enough chances and time to students for expressing their ideas and innovations, help the in the process of scientific development in order that they can increase in them the power of analyzing issues, criticizing scientifically, solving problems, and innovation and creation. The culture dominating the educational system should be in such a way that risk taking be encouraged in students in order that they do not avoid expressing their ideas and innovations because of the fear of being ridiculed by their classmates and professors. It is suggested that professors create appropriate strategies and give independence to student in order to make them take risks and welcome activities require risk taking. Furthermore, creating vivacity and dynamics via different recreational programs can revive creativity in students. Holding workshops and educational courses as well as making professors familiar with creative teaching methods are highly recommended. Moreover, regarding the influence of academic self-efficacy, it is recommended that students should be aware their problem solving believes; therefore, to enhance this awareness, planning and performing training is necessary for the increase in self-efficacy. Furthermore, training and conducting researches and cases studies can be suitable in accessing desired aims.

\section{References}

Aboma, O. (2009). Predicting first year university students' academic success. Electronic Journal of Research in Educational Psychology, 7,1053-1072.

Akinsola, M. K. (2008). Relationship of some psychological variables in predicting problem solving ability of in-service mathematics teachers. The Montana Mathematics Enthusiast, 5,79-100.

Aschen Brener M. S. (2008). "Analysis of creative and effective teaching behaviors of university instructors". Dissertation, Columbia: University of Missouri.

Atadokht, A. et al. (2013). "The effect of training social problem solving on enhancing psychological well-being and tolerance of children with learning disorder". Learning Disabilities. 3 (2), 92-108.

Bell, A.C \& D' Zurilla, T. J. (2009). Problem-solving therapy for depression: A metaanalysis Clinical Psychology Review, 29, 348-353.

Dau Gaspar, O. (2011). "The teachers creative attitudes, an influence factor of the student's creative attitudes". International Conference on the Future of Education, 16-17 June, Florence, Italy.

Ekvall G. (1996). Organizational Climate for Creativity and Innovation. European Journal of Work and Organizational Psychology. 5(1): $105-122$.

Ekvall G.(1999). Creative Climate. In Mark A. Runco, \& Steven R. Pritzker (Eds.),Encyclopedia of creativity,Vol New York: Academic Press; 1999: 403-413.

Gore, P. A. Jr. (2006). Academic self-efficacy as a predictor of college outcomes: Two incremental validity studies. Journal of career assessment,14 (1), 92-115.

Heppner, P. P. (1988). The Problem-Solving Inventory: Manual. Palo Alto, CA, Consulting Psychologist Press.

Hungies, S. K., Changeiywo, J. M. (2009). "Influence of creativity teaching strategy on student's performance and motivation in the topic "Energy" in secondary school physics in Nakuru district, Kenya". Journal of Technology and Education in Nigeria, 14(1- 2), pp: 101-114.

Kerka,M, Gory.K ,(1999). Creativity in adulthood. Eric clearing house on adult Columbus.

Khosravi, Z. et al. (1998). "The role of mood states on female students assessment of their own problem solving abilities". Thought and Behavior. 4 (1), 35-96.

Knowles E, Delaney P.Lastingr eductions in Illegal moves following an increase in their cost: Evidence from river-crossing problems. J Exp Psychol 2000;31(2): 670-682.

Koslowsky,M. Smadar Lev ,(2009)"Moderating the collective and self-efficacy relationship", journal of Educational Administration , Vol.47Iss:4, pp.452-462.

Mahmoudi, H. et al. (2009). "Assessing professors' educational experience from higher education students' perspectives". Education Strategies. 2 (2). 13-16.

Narimani, M. \& Vahidi, Z. (2013). "Comparing emotional deficiencies, self-efficacy beliefs, and self-esteem among students with and without learning disability". Learning Disabilities. 3 (2), 78-91.

Nasri Sadegh, S. et al. (2014). "Structural modeling of the relationship of self-efficacy, metacognition with assessing high school students' problem solving". School Psychology. 3 (3), 106-121. 
Perla, F. \& O'Donnell, B. (2004). Encouraging problem solving in orientation and mobility.Journal of Visual Impairment \& Blindness, 98, 47-52.

Perry, J. C., DeWine, D. B., Duffy R. D. \& Vance, K. S. (2007).The academic self-efficacy of urban youth: A mixed-methods study of a school-to-work program. Journal of Career Development, 34 (2), 103-126.

Pintrich, P. R. \& De Groot, E. V. (1990). Motivational and Self-regulated learning components of classroom academic performance. Journal of Educational Psychology, 82(1), 33-40.

Shokri, O. et al. (2011). "Psychometric studies of academic self-efficacy beliefs questionnaire. Studies on Teaching and Learning". 3 (2), 45-61.

Solberg, V. S., Hale, J. B., Villarreal, P., and Kavanagh, J. (1993). Development of the college stress inventory for use with Hispanic populations: A confirmatory analytic approach. Hispanic Journal of Behavioral Sciences, 15(4), 490-497.

Torrance, E. P (1990). The manifesto: A guide to developng a creativecareer. Westport, CT: Ablex.

Zajacova, A., Lynch, S. M., \& Espenshade, T. J. (2005). Selfefficacy, Stress, and academic success in college. Research in Higher Education, 46 (6), 678-706. 